ISSN 0974-3618 (Print) 0974-360X (Online) www.rjptonline.org

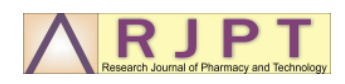

RESEARCH ARTICLE

\title{
Effectiveness of Toothpaste containing Pyrophosphate and Papain to Inhibit Calculus Formation in patient using Fixed Orthodontic Appliance
}

\author{
I Gusti Aju Wahju Ardani ${ }^{1 *}$, Monika Nilam² ${ }^{2}$ Hana Arya Puspita ${ }^{2}$, Ida Bagus Narmada ${ }^{1}$ \\ ${ }^{1}$ Orthodontic Department, Faculty of Dental Medicine, Universitas Airlangga, Surabaya, Indonesia. \\ ${ }^{2}$ Undergraduate Student, Faculty of Dental Medicine, Universitas Airlangga, Surabaya, Indonesia. \\ *Corresponding Author E-mail: wahju_ardani@fkg.unair.ac.id
}

\begin{abstract}
:
Patients using fixed orthodontic appliance are more susceptible to calculus formation than patient without orthodontic treatment. Pyrophosphate and papain toothpaste can be used to reduce dental plaque and calculus accumulation. The aim of this study was to analyze the differences in the calcium level and phosphate level in saliva, also saliva $\mathrm{pH}$ in patient's after treated with toothpaste containing pyrophosphate and papain. This study was true experimental study with pre-test and post-test controls group design with random sampling. Sample size was $(n=20)$. Sample was 17-22 years old male or female patient using fixed orthodontic appliance. Sample divided into two groups: control group treated with placebo toothpaste and treatment group treated with toothpaste containing pyrophosphate and papain with blind method. Patients were instructed to brush their tooth twice a day daily. $3 \mathrm{ml}$ unstimulated saliva was collected on the Day 1, 3, and 5. Spectrophotometer Atom Absorbance (SAA) was used to measure calcium level and phosphate level in saliva, while saliva pH measurement using pH meters. Treatment group showed lowest mean (SD) calcium level [1.12(0.29]. Calcium level in treatment group between groups $(\mathrm{p}<0.05)$ was significantly different. Saliva $\mathrm{pH}$ was insignificantly different between groups ( $p>0.05)$. Treatment group showed lowest phosphate level in Day 5. Phosphate level in treatment group between groups $(\mathrm{p}<0.05)$ was significantly different. Toothpastes containing pyrophosphate and papain decreased calcium levels, phosphate levels effectively and maintaining normal salivary $\mathrm{pH}$ to inhibit calculus formation in patients using fixed orthodontic appliance.
\end{abstract}

KEYWORDS: Calcium level, Phosphate level, Pyrophosphate, Papain, saliva pH.

\section{INTRODUCTION:}

In patients using fixed orthodontic appliance, it is more difficult to maintain oral hygiene during treatment ${ }^{1,2,3}$. Orthodontic treatment with fixed orthodontic appliance such as the brackets and orthodontic molar bands dental plaque reservoir due to increased biofilm formation after insertion. ${ }^{1}$ Research proves that bracket insertion leads to an increase in biofilm formation accompanied by changes in microbial ecology $y^{1,2,4}$.

Received on 18.03.2019

Accepted on 18.05.2019

Research J. Pharm. and Tech 2019; 12(8): 3797-3801.

DOI: 10.5958/0974-360X.2019.00650.4
Patient with fixed orthodontic appliance have a difficulty to maintain oral hygiene ${ }^{2}$. Debris attachment easily occur due to the presence of fixed orthodontic brackets $^{5}$. The presence of plaque accumulation will lead to poor oral hygiene resulting in calculus and caries. In addition, inflammatory response in periodontal tissue $^{6}$. Oral Health should be maintained ${ }^{7}$. Another factor that plays an important role in calculus formation is saliva ${ }^{8,9}$. Saliva contains calcium ions, in combination with phosphate to form calcium phosphate, a solid inorganic material ${ }^{10,11}$.

Calcium and phosphate content in saliva serves as remineralization, osmotic regulator, buffer and calculus formation $^{12,13}$. The higher the concentration of calcium and phosphate in saliva, calculus formed easily ${ }^{14}$. Calculus was one of the etiology of periodontal disease ${ }^{15,16}$ 
Oral hygiene is an important factor during fixed orthodontic treatment, therefore, plaque control was performed to maintain oral hygiene ${ }^{17}$. Plaque control can be performed by toothbrushing ${ }^{18}$. Tooth brushing is one of the most commonly used selection to maintain oral hygiene, simplest, safely and effectively ${ }^{19,20}$.

Toothpaste can be used to reduce dental plaque and calculus accumulation. Toothpaste contains pyrophosphate and papain that can act as anti-tartar. Pyrosphosphate is added as tetrasodium pyrophosphate, tetrapotassium pyrophosphate or disodium pyrosphosphate. It has been shown that pyrosphosphate has a high affinity on the surface of hydroxyapatite (HA), possibly an interaction with calcium in the hydration layer. The interactions between hydroxyapatite and enamel surfaces, pyrosphosphate can decrease protein binding capacity and able to inhibit the formation of calcium phosphate ${ }^{21}$. Pyrophosphate is able to work by stabilizing calcium levels in saliva and inhibiting the growth of crystals that help calculus formation as well as antimicrobials. Papain is a proteolytic enzyme that has a function as bactericidal, bacteriostatic and anti-inflammatory agent ${ }^{22}$.

The aim of this study was to analyze the differences in the calcium level, phosphor level and saliva $\mathrm{pH}$ in fixed orthodontic patient's saliva after treated with toothpaste containing pyrophosphate and papain.

\section{MATERIAL AND METHODS: Ethical Clearance:}

This study has obtained a research ethical permit on human subjects provided by the ethics committee Faculty of Dental Medicine, Universitas Airlangga, Surabaya, East Java, Indonesia with number 183/KKEPK.FKG/VIII/2016 184/KKEPK.FKG/VIII/2016.

\section{Study Design:}

This research was a true experimental study with pretest and post-test controls group design with random sampling. Sample size was determined with Lameshow's methods ( $N=20, n=10$ /group). Sample was 17-22 years old male or female patient using fixed orthodontic appliance, which has supragingiva calculus in lower lingual anterior region. Sample divided into two groups: control group treated with placebo toothpaste and treatment group treated with toothpaste containing pyrophosphate and papain with blind method.

\section{Tooth paste preparation:}

We made tooth paste which contained papain and propyrophosphate. Toothpaste was made at Research Center, Faculty of Dental Medicine, University of Airlangga with the following stages: 5 grams of
Aluminium Phosphate taken and inserted into a glass beaker. 6 grams of Glycerine and 1 gram Sodium Alginate was added and stirred evenly. 0.1 grams of saccharin, 0.1gram of Sodium benzoate mixed with 10 $\mathrm{ml}$ of water mixed. After homogeneous $0.01 \mathrm{~mL}$ of peppermint oil is stirred until a paste is formed. After 6 hours (to remove the existing foam) then packed.

\section{Saliva Collection:}

In this study, there is a research procedure that is the selection of samples according to the criteria and the filling of the informed consent form. Patients were instructed to brush their teeth twice a day daily, morning after breakfast and night before sleep. $3 \mathrm{ml}$ unstimulated saliva was collected on the Day 1, 3, and 5 from each sample group. Calculus was cleaned after saliva collection by dental scaling procedure. Saliva $\mathrm{pH}$ measurement using $\mathrm{pH}$ meters

\section{Calcium and phosphate level examination:}

Spectrophotometer Atom Absorbance (SAA) was used to measure calcium level with wavelength of $241 \mathrm{n} / \mathrm{m} \mu$ and phosphate level with wavelength $283 \mathrm{~nm} / \mathrm{m} \mu$. Sample's saliva which is a viscous liquid weighed 1-2 grams, and inserted into a platinum grill plate, then dried in an oven at $100^{\circ} \mathrm{C}-150^{\circ} \mathrm{C}$ (moisture content), then incorporated furnish fuel, gradually burned to $600^{\circ} \mathrm{C}$ $800^{\circ} \mathrm{C}$. $20 \mathrm{ml}$ of $\mathrm{HCl}$ and $5 \mathrm{ml}$ of $\mathrm{HNO} 3$ was added and transferred to a $100-\mathrm{ml}$ quantity flask quantitatively. Aquades poured until it reaches the line mark then shaken until homogeneous, and filtered with filter paper, thus clear filtrate liquid obtained. This clear filtrate was transferred to a 50-ml cup glass. Capillary pipettes are installed and inserted into the atomic absorption spectrophotometer fuel and burned with acetylene fuel of blue fire oxygen, thus calcium obtained. Calcium then installed atomic absorption spectrophotometer filter in accordance with the metal in question, then measured the absorbance value of each compared with the standard calcium, thus calcium levels obtained. Standard absorbance is data for the calibration curve $\mathrm{e}^{23}$.

\section{Data Analysis:}

Data in normal distribution was analyzed using independent t-test. Statistical analysis was analyzed by means of Statistical Package for the Social Sciences (SPSS) 17.0 software for windows 8.1 (IBM Inc., Chicago, United States).

The result of Toothpaste with pyrophosphate and papain that we made can be seen in figure 1. Shapiro-Wilk normality test showed all groups normally distributed $(\mathrm{p}>0.05)$. Treatment group showed lowest mean \pm Standard Deviation (SD) calcium level (1.12 \pm 0.29$)$. There was a significant decrease in calcium level in treatment group between groups $(\mathrm{p}<0.05)$ (Table 1$)$, 
while there is no significant different between control groups and treatment groups ( $>0.05)$ (Table 2). Saliva $\mathrm{pH}$ was insignificant different between groups $(\mathrm{p}>0.05)$ (table 3). Treatment group showed lowest phosphate level in Day $5(0.24 \pm 0.69)$. There was a significant decrease in phosphate level in treatment group between groups $(\mathrm{p}<0.05)$ (Table 4$)$, while there is no significant different in phosphate level between control groups and treatment groups ( $>0.05)$ (Table 5).

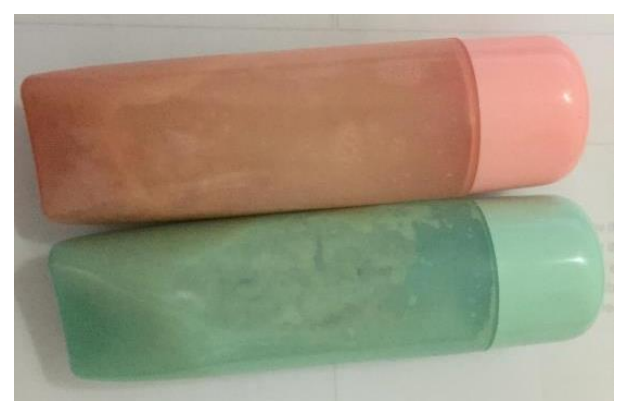

Fig. 1. Toothpaste that we made, A. placebo toothpaste (green); B. Toothpaste with pyrophosphate and papain (red).

Table 1. The Average and Standard Deviation of calcium level in saliva on Day 1,3 and 5 for control group and treatment group.

\begin{tabular}{|l|l|l|l|l|l|l|l|l|l|}
\hline & Day 1 & Day 3 & P & Day 3 & Day 5 & P & Day 1 & Day 5 & P \\
\hline $\begin{array}{l}\text { Treatment } \\
\text { Group }\end{array}$ & $1.65 \pm 0.29$ & $1.78 \pm 0.29$ & 0.006 & $1.78 \pm 0.29$ & $1.12 \pm 0.29$ & 0.000 & $1.65 \pm 0.29$ & $1.12 \pm 0.29$ & 0.002 \\
\hline $\begin{array}{l}\text { Control } \\
\text { Group }\end{array}$ & $1.58 \pm 0.28$ & $1.70 \pm 0.22$ & 0.042 & $1.70 \pm 0.22$ & $1.21 \pm 0.28$ & 0.007 & $1.58 \pm 0.28$ & $1.21 \pm 0.28$ & 0.029 \\
\hline
\end{tabular}

Information: significant at $\mathrm{p}<0.05$.

Table 2. The comparison results of calcium level in saliva between control group and treatment group on Day 1,3,5.

\begin{tabular}{|l|l|l|l|}
\hline & Treatment group & Control Group & P \\
\hline Day 1 & $1.65 \pm 0.29$ & $1.58 \pm 0.28$ & 0.740 \\
\hline Day 3 & $1.78 \pm 0.29$ & $1.70 \pm 0.22$ & 0.630 \\
\hline Day 4 & $1.12 \pm 0.29$ & $1.21 \pm 0.28$ & 0.646 \\
\hline
\end{tabular}

Information: significant at $\mathrm{p}<0.05$.

Table 3. The Average and Standard Deviation of saliva pH on Day 1,3 and 5 control group and treatment group.

Table 3. The Average and Standard Deviation of saliva pH on Day 1,3 and 5 control group and treatment group.
\begin{tabular}{|l|l|l|l|l|l|l|l|l|l|}
\hline & Day 1 & Day 3 & P & Day 3 & Day 5 & P & Day 1 & Day 5 & P \\
\hline Treatment Group & $7.42 \pm 0.49$ & $7.44 \pm 0.31$ & 0.880 & $7.44 \pm 0.31$ & $7.24 \pm 0.24$ & 0.024 & $7.42 \pm 0.49$ & $7.24 \pm 0.24$ & 0.185 \\
\hline Control Group & $7.69 \pm 0.29$ & $7.56 \pm 0.20$ & 0.456 & $7.56 \pm 0.20$ & $7.63 \pm 0.30$ & 0.527 & $7.69 \pm 0.29$ & $7.63 \pm 0.30$ & 0.791 \\
\hline
\end{tabular}

Information: significant at $\mathrm{p}<0.05$.

Table 4. The Average and Standard Deviation of phosphate level in saliva on Day 1, 3 and 5 for control group and treatment group.

\begin{tabular}{|l|l|l|l|l|l|l|l|l|l|}
\hline & Day 1 & Day 3 & P & Day 3 & Day 5 & P & Day 1 & Day 5 & P \\
\hline $\begin{array}{l}\text { Control } \\
\text { Group }\end{array}$ & $0.31 \pm 0.11$ & $0.33 \pm 0.11$ & 0.526 & $0.33 \pm 0.11$ & $0.24 \pm 0.69$ & 0.057 & $0.31 \pm 0.11$ & $0.24 \pm 0.69$ & 0.031 \\
\hline $\begin{array}{l}\text { Treatment } \\
\text { Group }\end{array}$ & $0.28 \pm 0.60$ & $0.33 \pm 0.65$ & 0.017 & $0.33 \pm 0.65$ & $0.33 \pm 0.40$ & 0.002 & $0.28 \pm 0.60$ & $0.17 \pm 0.40$ & 0.001 \\
\hline
\end{tabular}

Table 5. The comparison results of phosphate level in saliva between control group and treatment group on Day 1,3,5.

\begin{tabular}{|l|l|l|l|}
\hline & Treatment Group & Control Group & P \\
\hline Day 1 & $0.28 \pm 0.60$ & $0.31 \pm 0.11$ & 0.636 \\
\hline Day 3 & $0.33 \pm 0.65$ & $0.33 \pm 0.11$ & 0.894 \\
\hline Day 5 & $0.17 \pm 0.40$ & $0.24 \pm 0.69$ & 0.103 \\
\hline
\end{tabular}

Information: significant at $\mathrm{p}<0.05$

The prevalence of malocclusion in the world nearly $70 \%$ of population that need orthodontic treatment ${ }^{24}$. This finding in accordance with Farahani study about the prevalence of malocclusion in Iran. The prevalence of Class I, Class II division 1, Class II division 2, and Class III malocclusions was 41.8, 24.1, 3.4, and 7.8 percent, respectively. Crowding was the most common dental anomaly in both arches. Crowding was a risk factor for gingivitis because it became a dental plaque accumulation site. Fixed orthodontic appliance was used to correct the malocclusion. Calculus formation can easily build up during fixed orthodontic treatment. Good oral hygiene should be maintained during fixed orthodontic treatment to decrease periodontal disease risk by using toothpastes containing pyrophosphate and papain $^{25,26}$.

In this study found changes in calcium levels in saliva after using toothpastes containing pyrophosphate and papain during fix orthodontic treatment. There are significant differences between groups. Calcium levels were significantly decreased on Day 5 treatment group. Differences in calcium levels in saliva due to tooth surface and the diet consumed by individual. Decrease in calcium levels is due to the influence of toothpastes containing anti tartar is pyrophosphate and papain. In this case has proven that toothpaste containing pyrophosphate and papain can decrease calcium level in saliva thus inhibit calculus formation in patients using fixed orthodontic appliance. Calcium levels in saliva greatly affect the oral cavity. The saturated calcium phosphate levels in the saliva will cause this compound to precipitate on the enamel, at first calcium phosphate precipitate and attached to the tooth surface as a soft layer, and over time this material will harden and more 
difficult to remove, resulting in the formation of dental calculus $^{11,27}$. Calcium levels in saliva indicate a possibility of plaque remineralization by calcium instead. Decreased of salivary mineralization, especially inorganic calcium saliva, salivary $\mathrm{pH}$ and Low salivary flow rate are risk factor of dental caries due to dental plaque is acidogenic thus enamel demineralization occur easily ${ }^{14}$.

In this study found changes in phosphate levels in saliva after using toothpastes containing pyrophosphate and papain during fix orthodontic treatment. There are significant differences between groups. Phosphate level in saliva decreased significantly in the treatment group Day 5. Phosphate levels decreased significantly due to the influence of toothpaste containing pyrophosphate and papain as anti-dental plaque. In this case it has been proved that toothpastes containing pyrophosphate and papain can decrease the phosphate level in saliva thus inhibit calculus formation in patients using fixed orthodontic appliance. Saturated calcium phosphate in saliva precipitate on the enamel ${ }^{14}$. Toothpaste with pyrophosphate and papain decrease phosphate levels in saliva effectively. Pyrophosphate works by stabilizing phosphate levels in saliva and inhibits the formation of calculus and act as an antimicrobial ${ }^{22}$. Pyrophosphate can inhibit the formation of supragingival calculus, whereas papain plays role as antibacterial and antiinflammatory agent ${ }^{21,22}$.

In this study found changes in salivary $\mathrm{pH}$ after using toothpastes containing pyrophosphate and papain during fix orthodontic treatment with significant differences between groups. The saliva $\mathrm{pH}$ decreases significantly on the Day 5 treatment group. It proves that toothpaste with active component such as pyrophosphate and papain effectively maintains normal saliva $\mathrm{pH}$. The increase of salivary $\mathrm{pH}$ may be influenced by the diets of each patient. Diet rich in protein and vegetables will tend to increase salivary $\mathrm{pH}$ due to the stimulation of secretion saliva flowrate associated with increased bicarbonate ions ${ }^{22}$. Salivary secretions may be affected by stimuli received by the salivary glands ${ }^{28}$. Differences in salivary $\mathrm{pH}$ may be affected by several factors: lack of control of individuals in consuming food ${ }^{29}$. Alkaline $\mathrm{pH}$ of saliva closely related to the increase in proteolytic activity of the organism and enhances the deposition of calcium phosphate, thereby increasing the plaque mineralization and increasing the $\mathrm{pH}$ has greater remineralization potential in dental plaque ${ }^{30}$. Some physiological processes influenced by $\mathrm{pH}$ are enzymatic activity, demineralization process and tissue remineralisation hard as well as acidic bonds. A decrease of salivary $\mathrm{pH}$ in the oral cavity could rapidly increase demineralization of tooth, whereas increase of salivary $\mathrm{pH}$ stimulate bacterial colonization and also increase the calculus formation ${ }^{28,29.30}$. The results of this study, saliva $\mathrm{pH}$ cannot be used as the main indicator but can be used as supporting indicator. Toothpastes containing pyrophosphate and papain decreased calcium levels, phosphate levels effectively and maintaining normal salivary $\mathrm{pH}$ to inhibit calculus formation in patients using fixed orthodontic appliance.

\section{ACKNOWLEDGEMENT:}

The authors would like to thank the Research Center, Airlangga University Dental Hospital, Orthodontic Department, Faculty of Dental Medicine, Airlangga University (UNAIR), Surabaya, East Java, Indonesia for helping our research.

\section{CONFLICT OF INTEREST:}

The authors declare no conflict of interest.

\section{REFERENCES:}

1. Stany CM, Vonny NS, Wowor W, Anindita, PS. Oral Hygine Status and Dental Caries of Patient with fixed orthodontic treatment. Journal e-GiGi (eG). 2013, 1(1):1-7.

2. Shahana RY, Muralidharan NP. Efficacy of Mouth Rinse in Maintaining Oral Health of Patients Attending Orthodontic Clinics. Research J. Pharm. and Tech. 2016, 9(11): 1991-1993.

3. Harishmitha PS, Karthikeyan M, Jayanthkumar. Chlorhexidine and its Role on Oral Health. Research J. Pharm. and Tech. 2014, 7(12):1492-1493.

4. Lindel ID, Elter C, Heuer W, Heidenblut T, Stiesch M, Polly RS. Comparative Analysis of Long-term Biofilm Formation on Metal and Ceramic Brackets. Angle Orthodontist. 2011, 81(5): 907-14.

5. Singh G. Fixed orthodontic appliances. In: Singh G, (ed). Text Book of Orthodontics. 2nd ed. New Delhi: Jaypee Publishers. $2007,449$.

6. Swathi R, Geetha RV. Oil Pulling and Oral Health: A Review. Research J. Pharm. and Tech. 2013, 6(12):1400-1401.

7. Subasree S, Murthykumar K, Dhanraj D. Effect of Aloe Vera in Oral Health - A Review. Research J. Pharm. and Tech. 2016, 9(5): 609-612.

8. Megananda HP, Eliza H, Neneng N. Preventive of Hard and Soft Tissue (periodontal tissue) Jakarta, EGC. 2011, (1):20-25.

9. Thirumalaisamy V, Gajendran P. Role of Salivary Interleukin 1 in Chronic Periodontitis: A Review. Research J. Pharm. and Tech. 2018, 11(1): 390-392.

10. Agarwal R, Lakshmi T. Salivary Enzymes as Biomarkers for Periodontitis - An Update. Research J. Pharm. and Tech. 2014, 7(1):98-100.

11. Llena-Puy $\mathrm{C}$. The role of saliva in maintaining oral health and as an aid to diagnosis. Med Oral Patol Oral Cir Bucal. 2006, 11(5):449-455.

12. Al-Hindawi SH, Luaibi NM, Al-Ghurabi BH. Estimation of Alkaline Phosphatase level in the Serum and Saliva of Hypothyroid Patients with and without Periodontitis. Research J. Pharm. and Tech. 2018, 11(7): 2993-2996.

13. Vasudevan DM, Sreekumari S, Kannaan V. Textbook of biochemistry for dental student. 2nd ed. India: Jaypee, 2012, (1):67-9.

14. Hegde MN, Tahiliani D, Shetty S, Devadiga D. Salivary alkaline phosphatase and calcium in cariesactive type II diabetes mellitus patients: an in vivo study. Contemp Clin Dent. 2014, 5(4):440-444.

15. Mulyawati Y. Calculus and how to eliminate it, Direktorat Gizi Masyarakat Gigi. Jakarta. 2008, 1(1):1-6.

16. Jain MR, Gheena S, Gopinath P. Comparison of Aerobic Bacteria in Saliva Samples of Chronic and Aggressive 
Periodontitis Patients- An In vitro Study. Research J. Pharm. and Tech. 2016, 9(8):1183-1186.

17. Mohire NC, Yadav AV, Gaikwad VK. Current Status of Oral Hygiene: A Clinical Survey Report. Research J. Pharm. and Tech. 2009, 2(2):274-282.

18. Natamiharja L, Yanti GN. Selection and Use of Toothbrushes in High School Students in Medan City. Dentika Dental Journal. 2005, 10(1), 28-32.

19. Neeraj KP, Aprajita M, Ruchi A. Efficacy of Different Designs of Toothbrushes in Plaque Removal. Journal of Oral Health Research. 2010, 1(1): 45-49.

20. Thanish AS. Awareness of Oral Hygiene among Children in Chennai. Research J. Pharm. and Tech. 2016, 9(8):1055-1058.

21. Embery G, Rølla G. Clinical and biological aspects of dentifrices. Oxford, Oxford University Press. 1992, 10-25.

22. Drake D, Grigsby B, Krotz DD. Growth-inhibitory effect of pyrophosphate on oral bacteria. Oral Microbiol Immunol. 1994, 9(1):25-8.

23. Bussadori SK, Guededs CC, Ram D. Chemo - mechanical Removal of caries in an Adolescent patient using a papain gel. J. Clin. Pediatric Dent. 2008, 32(1):177-180.

24. Simões RC, Goettems ML, Schuch HS, Torriani DD, Demarco FF. Impact of malocclusion on oral health-related quality of life of 8-12 years old schoolchildren in Southern Brazil. Brazilian Dent J. 2017, 28(1):105-112.

25. Farahani AB, Farahani AB, Eslamipour F. Malocclusion and occlusal traits in an urban Iranian population. An epidemiological study of 11- to 14-year-old children. Eur J Orthod. 2009, 31(5):477-84.

26. Farahani, AB. an insight into four orthodontic treatment need indices. Prog Orthod. 2011 Nov, 12(2):132-42.)

27. Fiyaz M, Ramesh A, Ramalingam K, Thomas B, Shetty S, Prakash P. Association of salivary calcium, phosphate, $\mathrm{pH}$, and flow rate on oral health: a study on 90 subjects. J Indian Soc Periodontol. 2013, 17(4):454-460.

28. Emeruwa AC. Antibacterial substance from Carica Papaya fruit extract. J Nat Prod. 1982, 45(2):123-127.

29. Rantonen P. Salivary flow and composition in healthy and disease adults. Dissertation. Helsinki: Helsinki University Central Hospital. 2003, 16-69.

30. Rajesh KS, Zareena, Hegde S, Arun Kumar MS. Assessment of salivary calcium, phosphate, magnesium, $\mathrm{pH}$, and flowrate in healthy subjects, periodontitis, and dental caries. Contemp Clin Dent. 2015, 6:461-65. 